\title{
Effects of Acute Stimulant Medication on Cerebral Metabolism in Adults with Hyperactivity
}

John A. Matochik, Ph.D., Thomas E. Nordahl, M.D., Ph.D., Michael Gross, M.D., William E. Semple, Ph.D., A. Catherine King, Robert M. Cohen, M.D., Ph.D., and Alan J. Zametkin, M.D.

Recent work in our laboratory has demonstrated both global and regional reductions in cerebral glucose metabolism in adult subjects with attention-deficit hyperactivity disorder (ADHD). The purpose of the present study was to examine the effects of an acute dose of stimulant medication on cerebral metabolism in adults with ADHD using positron emission tomography with fluorodeoxyglucose-18 as the tracer. Each subject underwent scanning twice, once off-drug and again after receiving a single oral dose of either dextroamphetamine $(0.25 \mathrm{mg} / \mathrm{kg})$ or methylphenidate $(0.35 \mathrm{mg} / \mathrm{kg})$. Subjects completed behavioral self-report measures before and after the scan and performed an auditory continuous performance task during the tracer uptake period. Neither drug changed global metabolism. Both drugs increased systolic blood pressure, and dextroamphetamine improved performance on the auditory attention task. Each stimulant produced a differential pattern of increases and decreases in regional metabolism throughout the regions of interest that were sampled. Rather than increasing glucose utilization in specific brain regions with lowered metabolic rates in adults with ADHD, stimulants may act by altering glucose use throughout the brain.

[Neuropsychopharmacology 8:377-386, 1993]
KEY WORDS: Positron emission tomography; Glucose metabolism; Hyperactivity; Attention-deficit disorder; Dextroamphetamine; Methylphenidate

Attention-deficit hyperactivity disorder (ADHD) affects from $2 \%$ to $5 \%$ of school-age children (Barkley, 1981). Approximately $40 \%$ to $60 \%$ of these children continue to manifest symptoms of the disorder into adulthood (Gittleman et al. 1985; Kane et al. 1990; Weiss et

From the Section on Clinical Brain Imaging, Laboratory of Cerebral Metabolism, National Institute of Mental Health, National Institutes of Health, Bethesda, Maryland.

Address correspondence to: John A. Matochik, Ph.D., National Institute of Mental Health, Section on Clinical Brain Imaging, NIH, Bldg. 10, Room 4N317, Bethesda, MD 20892.

Received October 9, 1992; revised February 2, 1993; accepted February 7, 1993. al. 1985). Despite a large number of research studies, consistent biologic differences between hyperactive subjects and unaffected controls have been difficult to establish. In an attempt to demonstrate reliable and meaningful neurobiologic differences, we have utilized the technique of positron emission tomography (PET) of the brain with $\left[{ }^{18} \mathrm{~F}\right]$-2-fluoro-2-deoxy-D-glucose, a radioactively labeled glucose analog, to measure cerebral metabolism. Recent work in our laboratory has demonstrated both global and regional reductions in cerebral glucose metabolism in adult subjects who had been hyperactive from childhood (Zametkin et al. 1990). Compared to controls, the largest decreases in metabolism occurred in the premotor and prefrontal cortex. These brain areas are believed to be important in motor control and attentional processes (Mesulam 1986; Wise 1985). 
The purpose of the present study was to assess the effects of stimulant medication on brain metabolism in ADHD subjects. We examined the hypothesis that treatment with an acute dose of stimulant medication might normalize the reduced brain metabolism of ADHD subjects (Zametkin et al. 1990). Psychostimulant treatment has been effective in the treatment of adults diagnosed with ADHD (Wender et al. 1985) as well as school-age children (Barkley 1977). The class II (controlled) central nervous system stimulants, dextroamphetamine and methylphenidate, have become the drugs of choice in clinical management (DuPaul and Barkley 1990). We studied both stimulants because clinical experience has suggested that some subjects will respond unfavorably to one drug but favorably to another. Despite their efficacy, the neurobiologic mechanisms whereby these drugs enable both children and adults to maintain attention for longer periods of time are not fully understood. To evaluate the effects of stimulants on cerebral metabolism in adults with ADHD, two experiments were conducted in which each subject underwent two PET scans, one scan before receiving drug (off-drug) and the second after administration of an acute dose of either dextroamphetamine or methylphenidate.

\section{METHODS}

This research was approved by the Human Subjects Protection Committee of the National Institute of Mental Health and the Radiation Safety Committee of the National Institutes of Health. Informed consent was obtained from all subjects in the study.

\section{Subjects}

A total of 27 adult outpatients were selected to participate in this study. In experiment 1 , the metabolic effects of an acute dose of dextroamphetamine were compared to the off-drug condition in 13 subjects. Fourteen other subjects were studied in experiment 2 , before and after an acute dose of methylphenidate. The following criteria had to be met for inclusion in the study: DSMIII-R diagnosis of ADHD (APA 1987); Utah criteria for attention-deficit disorder in adulthood (Wender et al. 1981, 1985); a definite childhood history of attentiondeficit disorder with hyperactivity; and no history of other major psychiatric disorders, including alcohol or substance abuse problems.

The presence and severity of other psychiatric disorders were assessed by the Schedule for Affective Disorders and Schizophrenia (Endicott and Spitzer 1978) and the Global Assessment Scale (Endicott et al. 1976), both administered by a board-certified psychiatrist in structured clinical interviews. A modified version of the Conners Abbreviated Rating Scale (the Parent's Rating Scale; Wender et al. 1981), which measures severity of hyperactivity, was completed retrospectively by parents of the hyperactive adults, by adults with hyperactivity, and by their spouse or a close friend. All subjects reported having considerable difficulty with both restlessness and inattention. Twenty-three were righthanded and four were left-handed. Demographic and clinical profiles of subjects are shown in Table 1.

\section{Stimulant Treatment}

Stimulant treatment consisted of a single oral dose of either dextroamphetamine sulfate $(0.25 \mathrm{mg} / \mathrm{kg})$ or methylphenidate hydrochloride $(0.35 \mathrm{mg} / \mathrm{kg})$ administered 90 minutes prior to glucose uptake. None of the subjects were on medications for at least 1 month prior to beginning the study, and most had never been treated with stimulant medications. Blood samples for drug levels were drawn at 120 and 180 minutes after drug administration. Plasma samples were separated and stored at $-80^{\circ} \mathrm{C}$ prior to assay by gas chromatography. Vital signs (blood pressure and heart rate) were recorded during the on-drug scan.

Table 1. Clinical and Demographic Profile of ADHD Subjects

\begin{tabular}{lcc}
\hline Characteristic & $\begin{array}{c}\text { Dextroamphetamine } \\
(\boldsymbol{n}=\mathbf{1 3 )}\end{array}$ & $\begin{array}{c}\text { Methylphenidate } \\
(\boldsymbol{n}=\mathbf{1 4})\end{array}$ \\
\hline Age (years) & $36.8 \pm 5.1^{a}$ & $38.1 \pm 11.2$ \\
Sex (M/F) & $9 / 4$ & $11 / 3$ \\
Conners Rating Scale ${ }^{b}$ & $18.1 \pm 8.4$ & $13.6 \pm 7.9$ \\
by parent & $16.6 \pm 4.3$ & $15.5 \pm 4.9$ \\
by self & $15.6 \pm 7.5$ & $15.5 \pm 6.3$ \\
by spouse/other & & \\
\hline${ }^{a}$ Means \pm SD. &
\end{tabular}




\section{Behavioral Task}

An auditory continuous performance task (CPT) was performed by all subjects during the on-drug and offdrug PET scans. The task consisted of a computergenerated series of $500-\mathrm{Hz}$ tones of 1 -second duration and 2-second interstimulus interval, with intensities of 67,75 , or $86 \mathrm{~dB}$. Subjects were required to press a handheld response button (usually with the left hand) when the lowest volume tone was detected through earphones. Performance was measured by correct identifcations of target tone (hits) and incorrect identifications of distracting tones (false alarms). A total of 220 targets and 440 distractors were presented. The auditory attention task was chosen because previous research had localized its effects on cerebral metabolism (Cohen et al. 1988) and to control for extraneous stimulation and internal mental activity during the scan. All subjects were trained in the task to minimize the effects of learning on metabolism.

\section{Positron Emission Tomography}

Subjects remained in the supine position with eyes covered during the scanning procedure. The subject's head was fixed in position by a hexalite plastic mask, which was molded to the shape of the head and attached to the scanner headrest. The CPT task was started several minutes before intravenous injection of 4 to $5 \mathrm{mCi}$ (148 to $185 \mathrm{MBq}$ ) of $\left[{ }^{18} \mathrm{~F}\right]$-2-fluoro-2-deoxy-D-glucose and continued for 30 minutes during the uptake period. Stimulant medication was administered 90 minutes prior to glucose injection on the day of the on-drug scan. Twenty-eight images or slices (four sets from seven planes) were obtained from each subject, starting at 5 $\mathrm{mm}$ above the plane parallel to the canthomeatal line. Scans were performed with a Scanditronix (Essex, MA) scanner with 5- to 6-mm full-width half-maximum in plane resolution and a interslice interval of approximately $3.5 \mathrm{~mm}$. Prior to glucose injection, a transmission scan was performed to correct for attenuation. Plasma radioactivity and glucose concentration were calculated from blood samples obtained during the uptake period and scan from a catheter inserted into the radial artery (generally on the right side). The two PET scans were performed 1 to 4 months apart with the order of the scans counterbalanced as a control for order effects.

After the scanning procedure, the level of anxiety and mood during the scan and CPT task were rated by the subject using the State-Trait Anxiety Inventory (STAI) (Spielberger et al. 1970) and the Profile of Mood States (POMS) (McNair et al. 1971). The POMS is a 65item adjective rating scale that has been factor analyzed into six scales: tension-anxiety, depression-dejection, anger-hostility, vigor-activity, confusion-bewilderment, and fatigue-inertia. The POMS analysis was based on these six scales and one derived scale, arousal = (tension + vigor) - (fatigue + confusion), (de Wit et al. 1991; Johanson and Uhlenhuth 1980). A 28-item "How I Feel" questionnaire (see Rapoport et al. 1980) was completed by the subject before the on-drug scan and immediately afterward to assess the effect of drug administration.

\section{Analysis of PET Images}

Raw pixel values were converted to glucose metabolic rates in milligrams of glucose per 100 grams of tissue per minute using a modification (Brooks 1982) of the Sokoloff operational equation (Phelps et al. 1979) and a lumped constant of 0.418 (Huang et al. 1980). For extraction of regional metabolic rates, 60 regions of interest (ROIs) were measured in five standard transaxial planes (Fig. 1). Plane A was characterized by the presence of bilateral white-matter structures corresponding to a horizontal section of the corona radiata above the level of the corpus callosum. Plane B was selected at a level above the body of the corpus callosum containing the midcingulate region and bilateral white-matter strips. Plane $C$ contained the body of the corpus callosum. Plane D was defined by the presence of the basal ganglia, internal capsule, and the thalamus. The lowest plane, plane E, was selected as the plane below the main basal ganglia plane which contained the lower frontal and temporal lobes and the hippocampal gyrus. The planes for analysis and the ROIs were selected by two independent raters, blind to the identity and treatment of the subject. The regions of interest (rectangular boxes) were placed on each subject's image through neuroanatomic matching to a standard template (Clark et al. 1985) which was based on the human brain atlas of Matsui and Hirano (1978). Interrater reliability over the 60 regions is $r=0.95$ (Pearson correlation).

Global glucose metabolic rate refers to the estimate of the mean values for glucose metabolism from all the gray matter-rich areas of the cortex that we sampled. Regional glucose metabolic rates are averages of the normalized values on metabolism from the ROIs. Normalization was performed by dividing the absolute glucose metabolic rate for the ROI by the global glucose metabolic rate (region/global) for each subject. The ratio data, which reduces the effects of individual variability on regional metabolism, constituted the raw data for statistical analysis.

\section{Statistical Analysis}

The data were analyzed by parametric statistical tests. Comparisons of on-drug and off-drug differences were evaluated by two-tailed paired $t$ tests. Corrections for 


\section{LEFT}

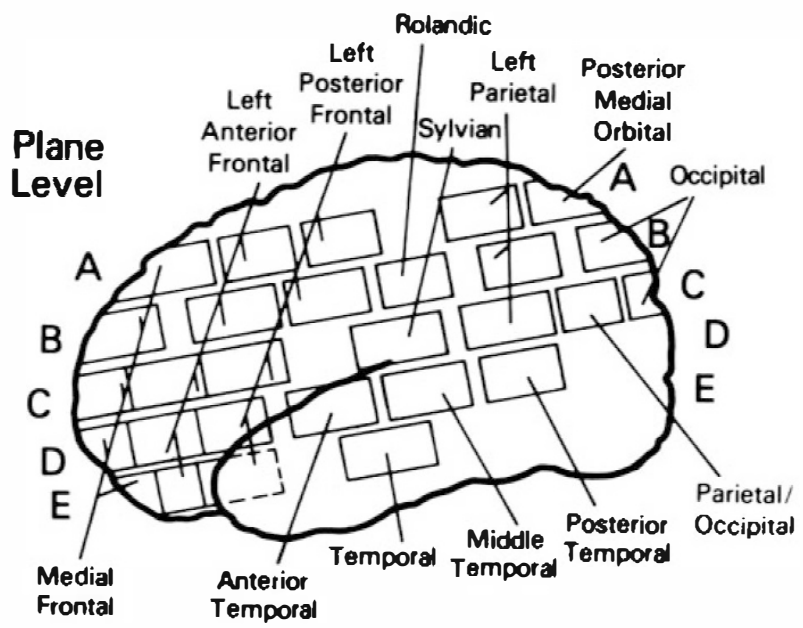

RIGHT

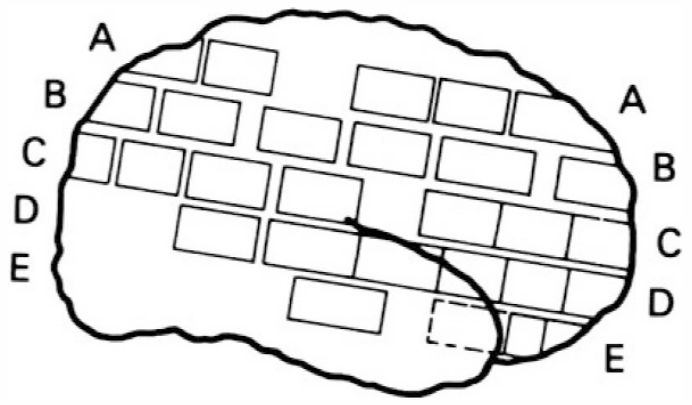

Figure 1. Schematic representation of the ROIs sampled in the left and right hemispheres. Regions labeled as medial, although sampled from the medial portion of the cortex, are represented when possible as incomplete boxes on the lateral surface of the left hemisphere. Additional ROIs not pictured are left and right thalamus, caudate (head area), putamen (anterior and posterior regions), hippocampus, and the midcingulate region. Total number of ROIs $=60$.

multiple comparisons (e.g., Bonferroni adjustments) were not employed. Individual $t$ tests corrected for large numbers of comparisons are relatively powerless to detect real differences if they exist (i.e., increase in type II errors). Given the difficulty and expense of obtaining large sample sizes and the small differences expected compared to the variance generally obtained in PET studies, we considered results with $p<.05$ statistically significant in the present study. Due to the exploratory nature of this research, we did not consider it appropriate to limit the number of brain regions investigated (total number of comparisons $=60$ ). Since the probability of type I errors is not strictly controlled for, some within-group differences may have resulted from random factors. Because significant $p$ values only indicate that the differences were due to more than random variation and the inherent power limitations of the present study, the effect size was additionally calculated for each ROI using Cohen's $d$ statistic (Rosenthal and Rosnow 1991). Effect size refers to the strength of the treatment effect or alternatively, the degree of departure (or distance) from the null hypothesis and thus, can be considered a measure of practical significance.

\section{RESULTS}

\section{Experiment 1: Effects of Dextroamphetamine}

Global Metabolic Rate. Because we were unable to identify a satisfactory match for plane A in two subjects, the global rate for subjects receiving dextroamphetamine was calculated from all the cortical regions we examined in planes B through $\mathrm{E}$. The normalized region values were also based on the global metabolic rate obtained from four planes instead of five. Comparison of the off-drug and on-drug scans revealed no difference in the rate of global metabolism $(8.75 \pm 1.01$ vs. $8.63 \pm 0.87 \mathrm{mg}$ glucose $/ 100 \mathrm{~g}$ tissue/min). Eight of the subjects showed an insignificant decrease in metabolism, whereas the other five tended to have slightly higher rates during the on-drug scan.

Regional Metabolic Rate. With the individual ROIs normalized (divided by global rate), metabolism of seven regions significantly changed $(p<.05)$ in response to dextroamphetamine treatment as depicted in Figure 2. The number of significant differences with dextroamphetamine are double what would be expected by chance alone. Determination of the effect size on the difference score for each ROI revealed a different metabolic pattern. Based on a "large" effect size arbitrarily defined as $d$ greater than 0.80 (i.e., the means of the two conditions are separated by 0.8 standard deviations or more), 16 brain regions including the seven areas with significant $p$ values met this criteria. Seven of these regions had increased metabolism on-drug: anterior medial frontal in plane $(d=1.00)$; right posterior frontal (1.23), right anterior temporal (1.04), posterior temporal (1.65), and middle temporal (1.00) in plane D; and subcortical regions, right thalamus $(0.86)$ and caudate (1.49). The remaining nine regions had decreased metabolic rates after drug administration: occipital $(0.89)$ and right rolandic areas $(0.89)$ in plane $B$; left anterior frontal (1.09) in plane C; left (1.28) and right (1.02) anterior 


\section{Metabolic Effects of Dextroamphetamine}

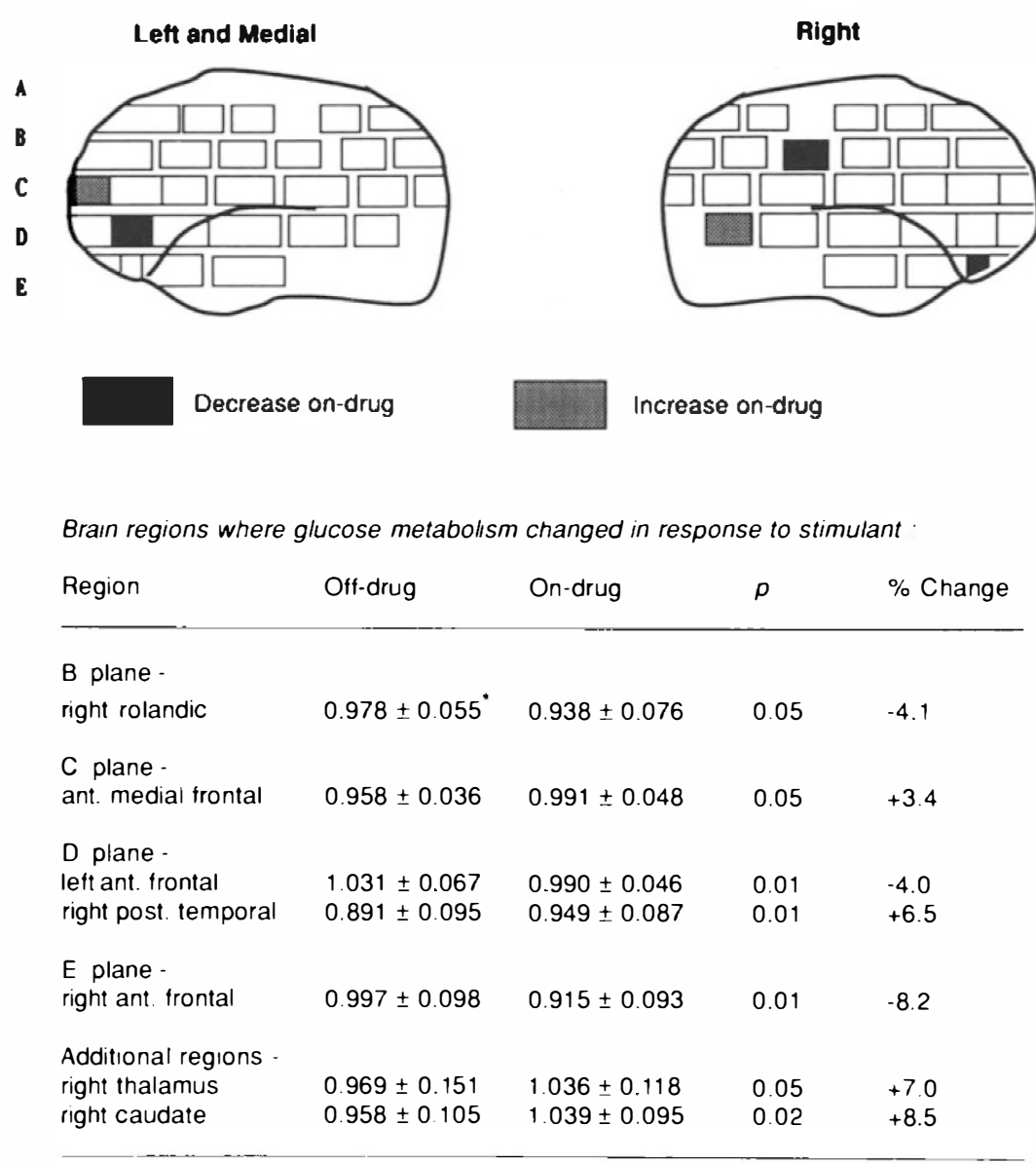

means $\pm \mathrm{SD}$
Figure 2. Regions of the brain where glucose metabolism changed in response to acute dextroamphetamine administration. frontal regions in plane $\mathrm{D}$; and anterior medial frontal (1.13), left (0.89) and right (1.45) anterior frontal, and right posterior frontal (1.03) regions in plane $\mathrm{E}$.

Behavior. As shown in Table 2, subjects on-drug were considerably more accurate on the CPT task, identifying significantly more of the target zones (hits). There were no differences in misidentifying the distracting tones (false alarms). There were no differences related to drug administration on the STAI or the POMS (Table 2). Five of the 28 responses on the 'How I Feel' questionnaire changed in relation to drug administration. Subjects, after administration of an acute dose of dextroamphetamine, reported feeling less "worried" $(p<$ $.02)$, "tired and slow" $(p<.007)$, and "scared" $(p<.007)$. Improvement was also noted on questions related to the current situation. Subjects noted they felt "things were less likely to go wrong" $(p<.02)$ or "happen unexpectedly" $(p<.03)$ during the scanning procedure.

Exploratory correlations between significant regional metabolic changes and changes in the behavioral rating scales were performed using the Kendall's tau- $b$ rank correlation. Increased metabolism in the right posterior temporal area of plane $\mathrm{D}$ was associated with the following changes on the "How I Feel" questionnaire: less "worried" (tau $=-0.48, p=.03)$, things were "less likely to go wrong" (tau $=-0.56, p=.02)$, or "happen unexpectedly" (tau $=-0.45, p=.04)$.

Drug Levels. At 120 minutes following administration of a single oral dose of dextroamphetamine, the mean plasma level was $44.0 \pm 7.9 \mathrm{ng} / \mathrm{mL}$. One hour later, at the end of the scan, the level was $47.7 \pm 11.2$.

Vital Signs. Blood pressure $(\mathrm{mm} / \mathrm{Hg})$ and heart rate (beats/minute) were recorded before administration of the drug $(0 \mathrm{~min})$ and 90 and 120 minutes later. Systolic pressure significantly increased after drug treatment $(F[2,22]=16.52, p<.0001)$ with higher readings at 90 and 120 minutes $(130 \pm 16$ and $131 \pm 17$, respectively) than at baseline (115 \pm 15$)$. The increases in systolic pressure were not significantly correlated with changes in regional metabolism. There was no change in diastolic pressure ( 0 minutes, $74 \pm 12 ; 90$ minutes, $77 \pm$ 
Table 2. Behavioral Effects of Acute Stimulant Administration

\begin{tabular}{|c|c|c|c|c|c|c|}
\hline \multirow[b]{2}{*}{ Behavior } & \multicolumn{2}{|c|}{ Methylphenidate } & \multirow[b]{2}{*}{$p$} & \multicolumn{2}{|c|}{ Dextroamphetamine } & \multirow[b]{2}{*}{$p$} \\
\hline & Off-drug & On-drug & & Off-drug & On-drug & \\
\hline \multicolumn{7}{|l|}{$\mathrm{CPT}^{a}$} \\
\hline hits & $158.1(38.9)^{b}$ & $152.2(41.8)$ & 0.5 & $172.2(31.9)$ & $200.5(20.6)$ & 0.01 \\
\hline false alarms & $6.1(4.9)$ & $6.6(5.8)$ & 1.0 & $13.8(19.8)$ & $9.0(12.4)$ & 0.6 \\
\hline STAI & $40.0(8.7)$ & $31.1(97.3)$ & 0.02 & $34.8(13.6)$ & $33.8(7.3)$ & 0.8 \\
\hline \multicolumn{7}{|l|}{ POMS } \\
\hline tension & $13.8(7.7)$ & $9.0(8.4)$ & 0.1 & $12.3(5.1)$ & $7.7(5.5)$ & 0.2 \\
\hline depression & $7.6(9.2)$ & $3.0(4.0)$ & 0.08 & $5.3(5.8)$ & $2.2(2.9)$ & 0.2 \\
\hline anger & $5.0(8.9)$ & $1.2(1.5)$ & 0.2 & $2.7(2.6)$ & $1.2(1.1)$ & 0.1 \\
\hline vigor & $13.5(5.1)$ & $16.5(5.7)$ & 0.1 & $11.0(9.6)$ & $13.5(7.6)$ & 0.07 \\
\hline confusion & $8.4(4.7)$ & $5.9(4.5)$ & 0.1 & $7.1(5.1)$ & $6.0(2.6)$ & 0.7 \\
\hline fatigue & $8.0(5.4)$ & $4.4(4.5)$ & 0.04 & $7.0(4.9)$ & $5.2(3.5)$ & 0.3 \\
\hline POMS total & $29.3(32.1)$ & $6.6(22.2)$ & 0.04 & $23.4(26.9)$ & $8.8(14.3)$ & 0.2 \\
\hline arousal & $10.9(7.3)$ & $15.2(10.7)$ & 0.2 & $9.2(14.2)$ & $10.1(13.5)$ & 0.6 \\
\hline
\end{tabular}

${ }^{a}$ Continuous performance task.

${ }^{b}$ Means (SD).

10; 120 minutes, $79 \pm 6$ ) or heart rate (average value $67.6 \pm 1.2)$.

\section{Experiment 2: Effects of Methylphenidate}

Global Metabolic Rate. Administration of a single oral dose of methylphenidate did not significantly alter global metabolism. The global rate before drug ad- ministration was $9.45 \pm 1.09$ compared to $9.07 \pm 1.45$ on-drug. Five of the subjects had slightly higher rates on-drug, whereas the remainder had very small decreases in metabolic rate.

Regional Metabolic Rate. As pictured in Figure 3, glucose metabolism in five brain regions changed signifcantly $(p<.05)$ in response to stimulant medication.

\section{Metabolic Effects of Methylphenidate}

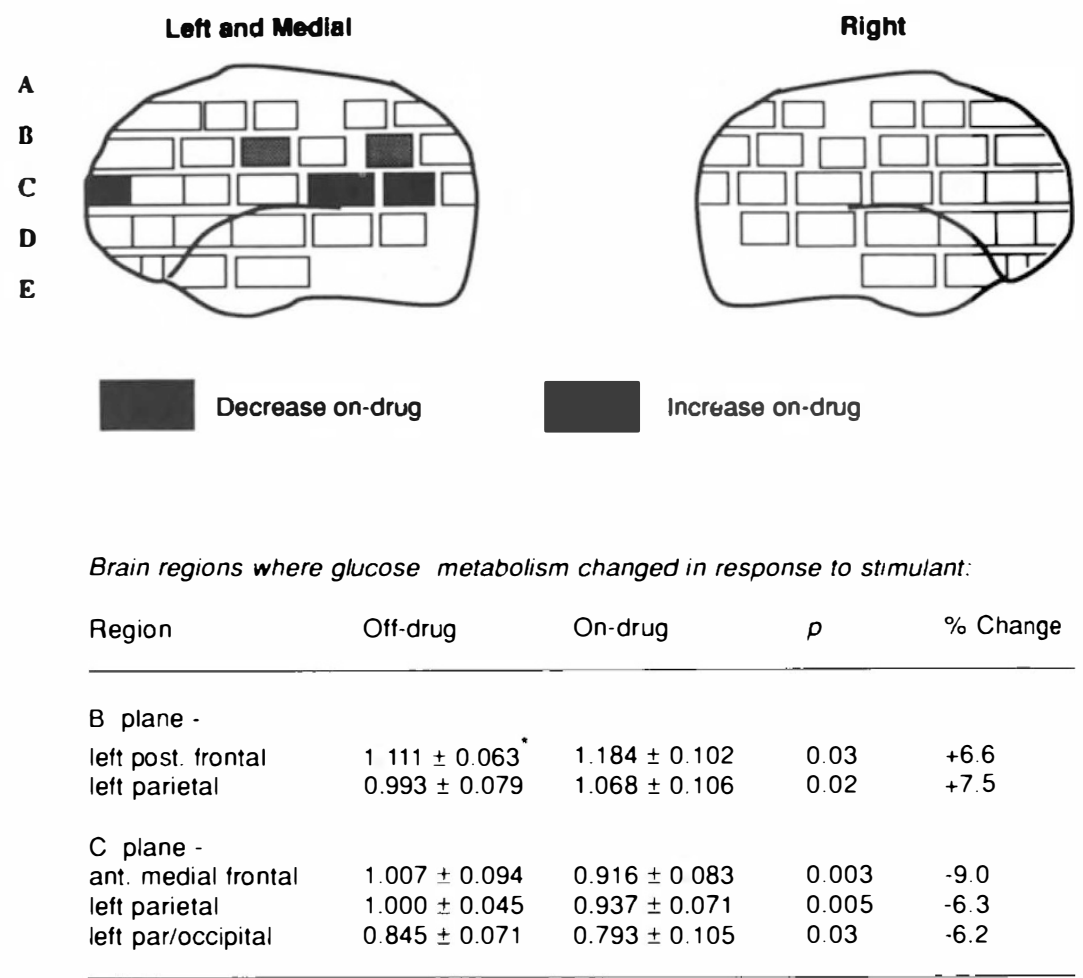

Figure 3. Regions of the brain where glucose metabolism changed in response to acute methylphenidate administration. 
Sixteen regions, however, had an effect size greater than 0.80 including the five areas with significant $p$ values. Nine of the brain regions with large effect sizes showed increased metabolic rates on-drug. These regions were the left anterior $(d=1.14)$ and posterior frontal $(0.82)$ regions in plane $A$; the anterior medial $(0.87)$, left anterior (0.82), and posterior (1.34) frontal areas, left (1.46) and right (0.83) parietal regions, and the right rolandic (1.01) in plane $B$; and the subcortical area, left posterior putamen $(0.81)$. The other seven regions had decreased rates of metabolism: in plane $C$, the anterior medial frontal (2.02), occipital (0.97), right parietal frontal (0.81), left (1.85) and right (1.01) parietal, and the left parietal/occipital (1.38) regions; and in plane $\mathrm{E}$, the left temporal region (1.05).

Behavior. As shown in Table 2, there were no differences in performance on the auditory attention task (CPT) as related to stimulant treatment. In contrast to the dextroamphetamine results, subjects receiving methylphenidate reported significant improvement on the STAI and POMS rating scales (Table 2). All subscales on the POMS showed a clear trend toward positive affect, with the fatigue and total POMS scores significantly different from the off-drug state. Similar to "How I Feel" responses after administration of dextroamphetamine, subjects taking methylphenidate reported feeling less "scared" $(p<.03)$. Improvement was also noted on questions related to the present situation. Subjects reported that things were less likely to "get messed up" $(p<.05)$, that "something bad might happen" $(p<.03)$, or that they were "not good at things" $(p<.04)$.

Decreased metabolism in the anterior medial frontal region of plane $\mathrm{C}$ was correlated with feeling "less scared" (tau $=0.58, p=.006)$ and that things were less likely to "get messed up" (tau $=0.53, p=.01$ ) on questions from the "How I Feel" scale. None of the other regional metabolic changes were correlated with changes on the behavioral rating scales.

Drug Levels. The mean plasma level at 120 minutes following drug administration was $12.3 \pm 6.2$ and at 180 minutes, $8.9 \pm 4.0 \mathrm{ng} / \mathrm{mL}$.

Vital Signs. Administration of an oral dose of methylphenidate increased systolic blood pressure after 120 minutes $(145 \pm 18)$ compared to baseline $(124 \pm 14)$ and 90 minutes $(133 \pm 14)(F[2,18]=10.56, p<.0009)$. The increase in systolic pressure at 120 minutes was correlated with changes in regional metabolism in only the left parietal region of plane B $(r=0.66, p<.05)$. Diastolic pressure was also increased following drug treatment $(F[2,18]=9.35, p<.002)$. Diastolic pressure readings at 90 minutes $(89 \pm 7)$ and 120 minutes $(91 \pm 10)$ were higher than at baseline $(81 \pm 7)$. There was no change in heart rate (average value $74 \pm 2$ ).

\section{DISCUSSION}

Changes in cerebral glucose metabolism after administration of a single dose of either dextroamphetamine or methylphenidate were investigated in the present study. These two commonly prescribed stimulants for the clinical management of ADHD had no effect on global metabolic rates, but had differential effects on regional metabolism and behavior. The acute drug levels for both dextroamphetamine and methylphenidate resulted in increased systolic pressure in all subjects, which is consistent with the expected changes in autonomic function due to stimulant medication. Thus we are confident that the drug levels obtained were adequate to observe possible metabolic changes at a clinically relevant dose.

\section{Effects of Dextroamphetamine}

Results from experiment 1 show no reduction in global or overall metabolism as a result of dextroamphetamine administration. These findings are in contrast to an earlier PET study (Wolkin et al. 1987), which reported small decreases in glucose utilization overall, as well as in six brain regions in adult schizophrenics. Also, several studies measuring cerebral blood flow in different subject populations have not found statistically significant global reductions after amphetamine administration (Daniel et al. 1991; Kahn et al. 1989; Mathew and Wilson 1985), although there is a trend toward global reduction. The human results are in contrast to the majority of findings in animal studies. Acute amphetamine administration in rats, for example, has produced diffusely increased blood flow and metabolism (Berntman et al. 1978; Porrino et al. 1984; Wechsler et al. 1979). The apparent differences between human and animal experiments may be related in part to the larger doses given to animals. In the study by Wolkin et al. (1987), the dose of amphetamine was about twice the dose level used in the present study.

The effects of acute doses of amphetamine on regional metabolism have not revealed a consistent pattern. One possible explanation is the use of activation tasks in some studies and not in others. In a recent abstract (Metz et al. 1991), none of the 20 brain regions studied in normal adults performing a visual monitoring task showed a significantchange after amphetamine treatment. Wolkin et al. (1987) reported significant decreases in glucose utilization in six brain regions (left and right frontal, temporal, and striatal areas) of adult schizophrenics. In the striatum, our ROIs measure separately the head of the caudate and the putamen, whereas the Wolkin study (1987) combined these areas for measurement. For the right caudate, we found a significant increase rather than a decrease in metabolism on-drug. Dextroamphetamine increases metabo- 
lism in the caudate nucleus and other nuclei in the basal ganglia and extrapyramidal system in rats (Porrino et al. 1984; Wechsler et al. 1979). In plane D, we found decreases in the left and right anterior frontal regions, and also the left anterior frontal region in plane $C$. These are regions that are similar to Wolkin's (1987). Only one of these areas (left anterior frontal) was statistically significant, but all three areas had effect sizes over 1.00. Recently, increases in cerebral blood flow were seen in the left dorsolateral prefrontal area during performance on the Wisconsin Card Sort Test when amphetamine was given to adult schizophrenics (Daniel et al. 1991). With amphetamine, the ADHD adults in our study showed noted improvement on the CPT in identifying the target zone. We found a significant metabolic increase near the medial frontal cortex, which is increased in normal subjects performing this task (Cohen et al. 1988). However, other regions that are increased in normal subjects performing the CPT were decreased in the adults with ADHD by drug administration: left anterior frontal in plane $C$ and the right anterior frontal region in plane $\mathrm{D}$.

As noted above, the oral dose of dextroamphetamine improved performance on our measure of attention. On-drug, the adults with ADHD correctly identified more of the target zones with the number of hits similar to normal subjects in earlier studies (Cohen et al. 1988). No improvement in the level of anxiety or mood was evident. The only subscale on the POMS that showed a trend toward improvement on-drug was the vigor-activity dimension. On-drug, the level of vigoractivity increased, which is consistent with an earlier study (Mathew and Wilson 1985) that reported a significant increase after an acute dose of dextroamphetamine.

\section{Effects of Methylphenidate}

Few studies have investigated the effects of methylphenidate on cerebral metabolism and blood flow despite the clinical efficacy of this drug. We found no change in the global rate of glucose utilization after an acute dose of methylphenidate. Three of the four regions that had decreased metabolism compared to normal controls in the earlier study (Zametkin et al. 1990) using normalized values were increased in the present study. The regions with increased metabolism were the left posterior frontal region in plane $A$, the anterior medial frontal and left anterior frontal regions in plane B, and although they had effect sizes over 0.8 , they did not reach statistical significance. One hypothesis of the efficacy of psychostimulants is that they may act by producing functional activity in brain regions with low glucose use in subjects with ADHD. The small sample size and large variance of the measures necessitates the use of effect size or treatment magnitude statistics to discern possible findings that may be important, although not statistically significant.

In rats, acute methylphenidate increases metabolism in the extrapyramidal system (Porrino et al. 1987) with reductions observed in the motor cortex (Bell et al. 1983). Blood flow studies in children with ADHD and other neurologic disorders have shown reduced flow in the anterior medial frontal regions and the head of the caudate nucleus (Lou et al. 1984, 1989). These studies suggested that blood flow in the caudate region may be increased by methylphenidate treatment. In the present study, we did not find an increase in glucose use in the left or right caudate after acute administration of methylphenidate.

In contrast to the effects of dextroamphetamine, our particular sample of adults with ADHD given a single dose of methylphenidate did not improve their performance on the auditory attention task as measured by the number of correct identifications. Their scores were lower, both on- and off-drug, than adults given dextroamphetamine on this simple measure of attention. Significant improvement, however, was noted on selfreport measures of anxiety and mood completed after the scanning procedure.

\section{Comparison of Dextroamphetamine and Methylphenidate}

Although the purpose of the present study was to compare each stimulant to its control condition, some preliminary comparisons between stimulants can be made. The two stimulant medications produced different regional metabolic patterns with both increases and decreases throughout the ROIs that we measured. In contrast, acute administration of cocaine, a widely abused psychostimulant, has been shown to reduce glucose metabolism globally and in several brain regions (London et al. 1990). Analysis of those regions in the present study with effect sizes of at least 0.8 reveals a pattern of effects not easily observed by looking at significant $p$ values. Methylphenidate action on metabolism is primarily in the middle and superior cortical areas (planes A, B, and C); whereas dextroamphetamine action is more pronounced in the inferior cortical areas (planes D and E) that we sampled. This casual analysis suggests the hypothesis that these two sympathomimetic drugs may be acting by different neural mechanisms to affect changes in physiology and behavior. This observation is supported by studies demonstrating differential effects of stimulants on urinary catecholamine excretion (Zametkin et al. 1985) and the observed clinical phenomenon of differential sensitivity of individual children to either dextroamphetamine or methylphenidate. The two stimulant drugs also differ in their mechanisms for stimulating the release of dopamine (McMillen 1983). Methylphenidate (and cocaine) 
promotes the release of dopamine from vesicular storage pools that are reserpine-sensitive, whereas amphetamines release dopamine from reserpine-insensitive pools that are dependent on newly formed amine. Both drugs, for example, could alter the ratio of dopamine to norepinephrine without changing global metabolism and still have specific regional effects.

\section{Implications for ADHD}

The clinical literature suggests that psychostimulant treatment is effective in the management of adults and children with ADHD. Acute treatment of ADHD adults with dextroamphetamine or methylphenidate in the present study did produce changes in regional glucose metabolism and behavior which may underlie the clinical effect. Our initial hypothesis that stimulants may work by increasing glucose utilization in specific brain regions that have low metabolic rates in ADHD adults is not supported by the present results. Rather, stimulants may act by a widespread pattern of increases and decreases in glucose utilization throughout the brain. Methylphenidate did increase metabolism in three of the four regions that previously werefound to havelowered metabolism (Zametkin et al. 1990). However, the mechanisms of stimulant drug action in ADHD are still dusive. Because both hyperactive subjects and normal controls respond in similar ways to stimulant treatment, the site of therapeutic action may not be the same as the neural substrates of the disorder. Stimulant treatment for ADHD generally involves chronic administration, that is, daily doses. Interestingly, studies in rats suggest that amphetamine may be more effective in increasing metabolism in subcortical structures by chronic, rather than acute, administration (Eisson et al. 1981; Orzi et al. 1983). Studies are currently in progress using PET to investigate metabolic changes in response to clinically adjusted chronic doses of dextroamphetamine and methylphenidate.

\section{ACKNOWLEDGMENTS}

The authors acknowledge the assistance of Glinda Fitzgerald, Garrett Bagley, Akia Talbot, and the PET technicians of the Department of Nuclear Medicine, NIH Clinical Center. Drug levels were analyzed by the laboratory of Thomas B. Cooper at the Nathan S. Kline Research Institute in Orangeburg, New York.

\section{REFERENCES}

American Psychiatric Association (1987): Diagnostic and Statistical Manual of Mental Disorders, 3rd ed, revised. Washington, DC, American Psychiatric Association Press

Barkley RA (1977): A review of stimulant drug research with hyperactive children. J Child Psychol Psychiatry 18: 137-165
Barkley RA (1981): Hyperactive Children: A Handbook for Diagnosis and Treatment. New York, Guilford Press

Bell RD, Alexander GM, Schwartzman RJ (1983): Methylphenidate decreases local glucose metabolism in the motor cortex. Pharmacol Biochem Behav 18:1-5

Berntman L, Carlsson C, Hagerdal M, Siesjö BK (1978): Circulatory and metabolic effects in the brain induced by amphetamine sulphate. Acta Physiol Scand 102:310-323

Brooks RA (1982): Alternative formula for glucose utilization using labeled deoxyglucose. J Nucl Med 2:538-539

Clark C, Carson R, Kessler R, Margolin R, Buchsbaum M, DeLisi L, King C, Cohen R (1985): Alternative statistical models for the examination of clinical positron emission tomography/fluorodeoxyglucose data. J Cereb Blood Flow Metab 5:142-150

Cohen RM, Semple WE, Gross M, Holcomb HH, Dowling MS, Nordahl TE (1988): Functional localization of subtained attention: Comparison to sensory stimulation in the absence of instruction. Neuropsychiatry Neuropsychol Behav Neurol 1:3-20

Daniel DG, Weinberger DR, Jones DW, Zigun JR, Coppola R, Handel S, Bigelow LB, Goldberg TE, Berman KF, Kleinman JE (1991): The effect of amphetamine on regional cerebral blood flow during cognitive activation in schizophrenia. J Neurosci 11:1907-1917

de Wit H, Metz J, Wagner N, Cooper M (1991): Effects of diazepam on cerebral metabolism and mood in normal volunteers. Neuropsychopharmacology 5:33-41

DuPaul GJ, Barkley RA (1990): Medication therapy. In Barkley RA (ed), Attention-Deficit Hyperactivity Disorder: A Handbook for Diagnosis and Treatment. New York, Guilford Press, pp 573-612

Eison MS, Eison AS, Ellison G (1981): The regional distribution of $d$-amphetamine and local glucose utilization in rat brain during continuous amphetamine administration. Exp Brain Res 43:281-288

Endicott J, Spitzer RL (1978): A diagnostic interview: The schedule for affective disorders and schizophrenia. Arch Gen Psychiatry 35:837-844

Endicott J, Spitzer RL, Fleiss JL, Cohen J (1976): The global assessment scale: A procedure for measuring overall severity of psychiatric disturbance. Arch Gen Psychiatry 33:766-771

Gittelman R, Mannuzza S, Shenker R, Bonagura N (1985): Hyperactive boys almost grow up. I. Psychiatric status. Arch Gen Psychiatry 42:937-947

Huang SC, Phelps ME, Hoffman EJ, Sideris K, Selin CJ, Kuhl DE (1980): Noninvasive determination of local cerebral metabolic rate of glucose in man. Am J Physiol 238: E69-E82

Johanson C, Uhlenhuth E (1980): Drug preference and mood in humans: Diazepam. Psychopharmacology 71:269-273

Kahn DA, Prohovnik I, Lucas LR, Sackeim HA (1989): Dissociated effects of amphetamine on arousal and cortical blood flow in humans. Biol Psychiatry 25:755-767

Kane R, Mikalac C, Benjamin S, Barkley RA (1990): Assessment and treatment of adults with ADHD. In Barkley RA (ed), Attention-Deficit Hyperactivity Disorder: A Handbook for Diagnosis and Treatment. New York, Guilford Press, pp 613-638 
London ED, Cascella NG, Wong DF, Phillips RL, Dannals RF, Links JM, Herning R, Grayson R, Jaffe JH, Wagner HN (1990): Cocaine-induced reduction of glucose utilization in human brain. Arch Gen Psychiatry 47:567-574

Lou HC, Henrikson L, Bruhn P, Psych C (1984): Focal cerebral hypoperfusion in children with dysphasia and/or attention deficit disorder. Arch Neurol 41:825-829

Lou HC, Henrikson L, Bruhn P, Broker H, Nelson JB (1989): Striatal dysfunction in attention deficit and hyperkinetic disorder. Arch Neurol 46:48-52

Mathew RJ, Wilson WH (1985): Dextroamphetamine-induced changes in regional cerebral blood flow. Psychopharmacology 87:298-302

Matsui T, Hirano A (1978): An Atlas of the Human Brain for Computerized Tomography. New York, Igaku-Shoin Medical

McMillen BA (1983): CNS stimulants: Two distinct mechanisms of action for amphetamine-like drugs. Trends Pharmacol Sci 19:429-432

McNair DM, Lorr M, Droppleman LF (1971): Profile of Mood States (Manual). San Diego, Educational and Industrial Testing Service

Mesulam MM (1986): Frontal cortex and behavior. Ann Neurol 19:320-325

Metz JT, de Wit H, Cooper M (1991): Amphetamine and regional cerebral metabolic rate: Effects of behavioral state and dose. J Cereb Blood Flow Metab 11(Suppl 2):390 (Abstract)

Orzi F, Dow-Edwards D, Jehle J, Kennedy C, Sokoloff L (1983): Comparative effects of acute and chronic administration of amphetamine on local cerebral glucose utilization in the conscious rat. J Cereb Blood Flow Metab 3:154-160

Phelps ME, Haung SC, Hoffman EJ, Selin C, Sokoloff L, Kuhl DE (1979): Tomographic measurement of local cerebral glucose metabolic rate in humans with $\left.{ }^{18} \mathrm{~F}\right] 1$-fluoro-2deoxy-D-glucose: Validation of method. Ann Neurol 6:371-388

Porrino LJ, Lucignani G, Dow-Edwards D, Sokoloff L (1984): Correlation of dose-dependent effects of acute amphetamine administration on behavior and local metabolism in rats. Brain Res 307:311-320

Porrino LJ, Lucignani G(1987): Different patterns of local brain energy metabolism associated with high and low doses of methylphenidate: Relevance to its action in hyperac tive children. Biol Psychiatry 22:126-138

Rapoport JL, BuchsbaumMS, Weingartner H, Zahn TP, Lud low C, Mikkelsen EJ (1980): Dextroamphetamine: Its cognitive and behavioral effects in normal and hyperactive boys and normal men. Arch Gen Psychiatry 37:933-943

Rosenthal R, Rosnow RL (1991): Essentials of Behavioral Re search: Methods and Data Analysis, 2nd ed. New York, McGraw-Hill

Spielberger CD, Gorsuch RL, Lushene RE (1970): Manual for the State-Trait Anxiety Inventory. Palo Alto, CA, Consulting Psychologists Press

Wechsler LR, Savaki HE, Sokoloff L (1979): Effects of $d$ - and $l$-amphetamine on local cerebral glucose utilization in the conscious rat. J Neurochem 32:15-22

Weiss G, Hechtman L, Milroy T, Perlman T (1985): Psychiatric status of hyperactives as adults: A controlled prospective 15-year follow-up of 63 hyperactive children. J Am Acad Child Adolesc Psychiatry 24:211-220

Wender PH, Reimherr FW, Wood DR (1981): Attention defic: disorder ('minimal brain dysfunction') in adults: A replication study of diagnosis and drug treatment. Arch Gen Psychiatry 38:449-456

Wender PH, Reimherr FW, Wood D, Ward M (1985): A corr trolled study of methylphenidate in the treatment of attention deficit disorder, residual type, in adults. Am I Psychiatry 142:547-552

Wise SP (1985): The primate premotor cortex: Past, present, and preparatory. Annu Rev Neurosci 8:1-19

Wolkin A, Angrist B, Wolf A, Brodie J, Wolkin B, Jaeger I Cancro R, Rotrosen J (1987): Effects of amphetamine on local cerebral metabolism in normal and schizophrenir subjects as determined by positron emission tomogrt phy. Psychopharmacology 92:241-246

Zametkin AJ, Karoum F, Linnoila M, Rapoport J, BrownGl. Chuang L, Wyatt RJ (1985): Stimulants, urinary catechot amines and indoleamines in hyperactivity: A compari son of methylphenidate and dextroamphetamine. An Gen Psychiatry 42:251-255

Zametkin AJ, Nordahl TE, Gross M, King AC, Semple WR Rumsey J, Hamburger S, Cohen RM (1990): Cerebral gto cose metabolism in adults with hyperactivity of childhood onset. N Engl J Med 323:1361-1366 
London ED, Cascella NG, Wong DF, Phillips RL, Dannals RF, Links JM, Herning R, Grayson R, Jaffe JH, Wagner HN (1990): Cocaine-induced reduction of glucose utilization in human brain. Arch Gen Psychiatry 47:567-574

Lou HC, Henrikson L, Bruhn P, Psych C (1984): Focal cerebral hypoperfusion in children with dysphasia and/or attention deficit disorder. Arch Neurol 41:825-829

Lou HC, Henrikson L, Bruhn P, Broker H, Nelson JB (1989): Striatal dysfunction in attention deficit and hyperkinetic disorder. Arch Neurol 46:48-52

Mathew RJ, Wilson WH (1985): Dextroamphetamine-induced changes in regional cerebral blood flow. Psychopharmacology 87:298-302

Matsui T, Hirano A (1978): An Atlas of the Human Brain for Computerized Tomography. New York, Igaku-Shoin Medical

McMillen BA (1983): CNS stimulants: Two distinct mechanisms of action for amphetamine-like drugs. Trends Pharmacol Sci 19:429-432

McNair DM, Lorr M, Droppleman LF (1971): Profile of Mood States (Manual). San Diego, Educational and Industrial Testing Service

Mesulam MM (1986): Frontal cortex and behavior. Ann Neurol 19:320-325

Metz JT, de Wit H, Cooper M (1991): Amphetamine and regional cerebral metabolic rate: Effects of behavioral state and dose. JCereb Blood Flow Metab 11(Suppl 2):390 (Abstract)

Orzi F, Dow-Edwards D, Jehle J, Kennedy C, Sokoloff L (1983): Comparative effects of acute and chronic administration of amphetamine on local cerebral glucose utilization in the conscious rat. J Cereb Blood Flow Metab 3:154-160

Phelps ME, Haung SC, Hoffman EJ, Selin C, Sokoloff L, Kuhl DE (1979): Tomographic measurement of local cerebral glucose metabolic rate in humans with $\left[{ }^{18} \mathrm{~F}\right] 1$-fluoro-2deoxy-D-glucose: Validation of method. Ann Neurol 6:371-388

Porrino LJ, Lucignani G, Dow-Edwards D, Sokoloff L (1984): Correlation of dose-dependent effects of acute amphetamine administration on behavior and local metabolism in rats. Brain Res 307:311-320

Porrino LJ, Lucignani G (1987): Different patterns of local brain energy metabolism associated with high and low doses of methylphenidate: Relevance to its action in hyperactive children. Biol Psychiatry 22:126-138

Rapoport JL, Buchsbaum MS, Weingartner H, Zahn TP, Ludlow C, Mikkelsen EJ (1980): Dextroamphetamine: Its cognitive and behavioral effects in normal and hyperactive boys and normal men. Arch Gen Psychiatry 37:933-943

Rosenthal R, Rosnow RL (1991): Essentials of Behavioral Research: Methods and Data Analysis, 2nd ed. New York, McGraw-Hill

Spielberger CD, Gorsuch RL, Lushene RE (1970): Manual for the State-Trait Anxiety Inventory. Palo Alto, CA, Consulting Psychologists Press

Wechsler LR, Savaki HE, Sokoloff L (1979): Effects of $d$ - and $l$-amphetamine on local cerebral glucose utilization in the conscious rat. J Neurochem 32:15-22

Weiss G, Hechtman L, Milroy T, Perlman T (1985): Psychiatric status of hyperactives as adults: A controlled prospective 15-year follow-up of 63 hyperactive children. JAm Acad Child Adolesc Psychiatry 24:211-220

Wender PH, Reimherr FW, Wood DR(1981): Attention deficit disorder ('minimal brain dysfunction') in adults: A replication study of diagnosis and drug treatment. Arch Gen Psychiatry 38:449-456

Wender PH, Reimherr FW, Wood D, Ward M (1985): A controlled study of methylphenidate in the treatment of attention deficit disorder, residual type, in adults. Am J Psychiatry 142:547-552

Wise SP (1985): The primate premotor cortex: Past, present, and preparatory. Annu Rev Neurosci 8:1-19

Wolkin A, Angrist B, Wolf A, Brodie J, Wolkin B, Jaeger J, Cancro R, Rotrosen J (1987): Effects of amphetamine on local cerebral metabolism in normal and schizophrenic subjects as determined by positron emission tomography. Psychopharmacology 92:241-246

Zametkin AJ, Karoum F, Linnoila M, Rapoport JL, Brown GL, Chuang L, Wyatt RJ (1985): Stimulants, urinary catecholamines and indoleamines in hyperactivity: A comparison of methylphenidate and dextroamphetamine. Arch Gen Psychiatry 42:251-255

Zametkin AJ, Nordahl TE, Gross M, King AC, Semple WE, Rumsey J, Hamburger S, Cohen RM (1990): Cerebral glucose metabolism in adults with hyperactivity of childhood onset. N Engl J Med 323:1361-1366 